MAR 191969

LIBRARY AND

DOCUMENTS SECTION

FAST BEAM CHOPPERS FOR THE

ELECTRON-RING ACCELERATOR

Andris Faltens and Cordon Kerns

$$
\text { February 7, } 1969
$$

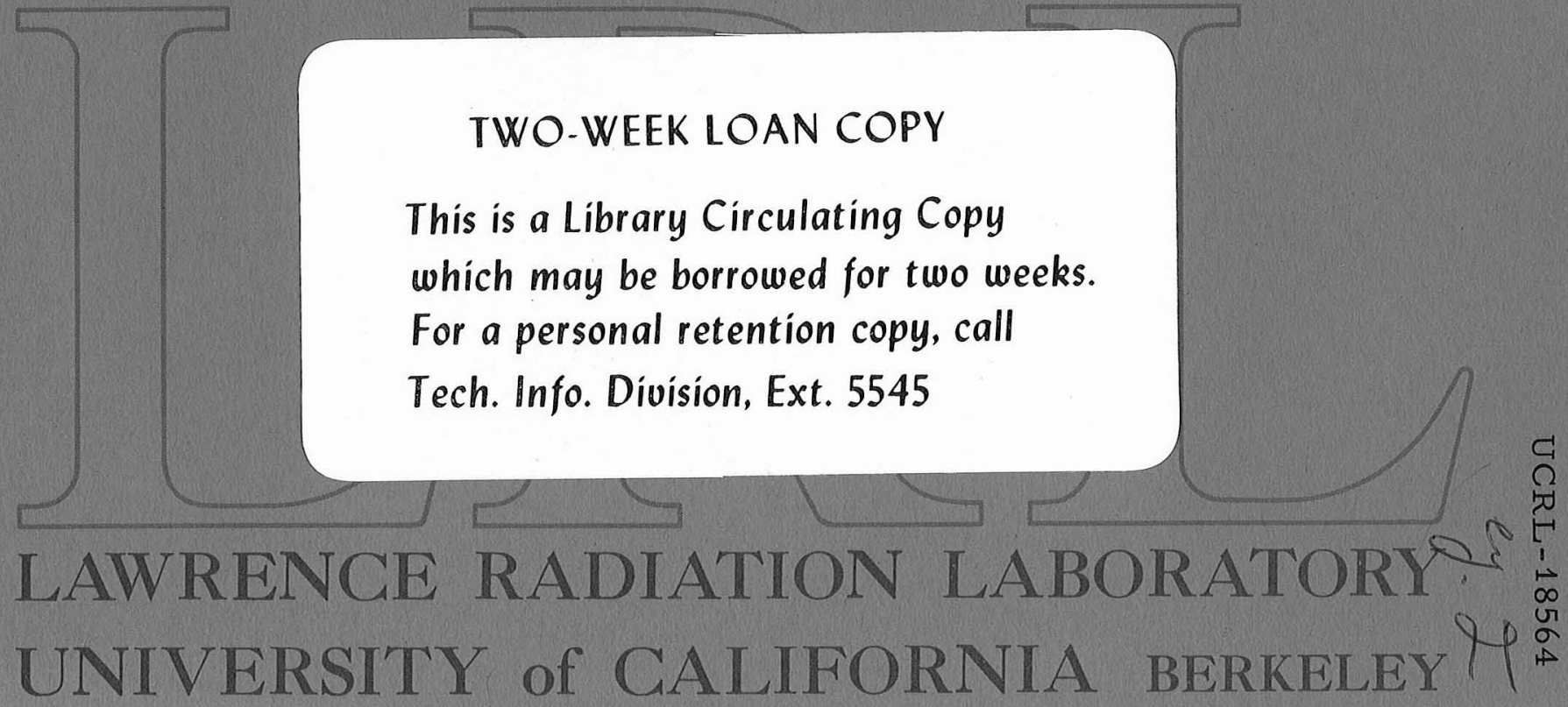




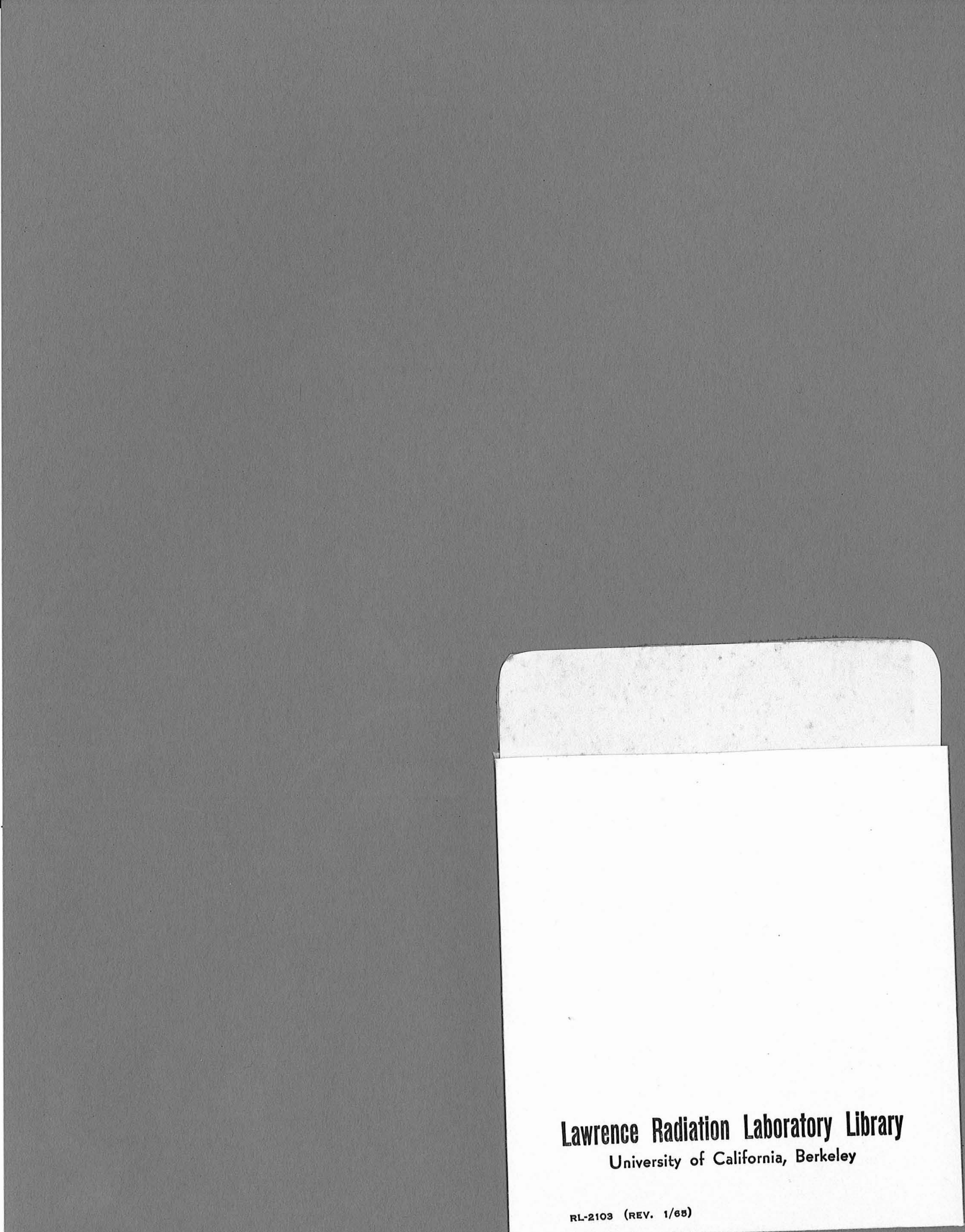

RL-2103 (REV. $1 / 00$ ) 
Presented at the National Particle Accelerator

UCRI-18564

Conference, Washington, D. C. , March 1969

Preprint

\section{UNIVERSITY OF CALIFORNIA}

Lawrence Radiation Laboratory

Berkeley, California

AEC Contract No. W-7405-eng-48

FAST BEAM CHOPPERS FOR THE

ELECTRON-RING ACCELERATOR

Andris Faltens and Cordon Kerns

February 7, 1969 



\title{
FAST BEAM CHOPPERS FOR THE ELECTRON-RING ACCELERATOR*
}

\author{
Andris Faltens and Cordon Kerns \\ Lawrence Radiation Laboratory \\ University of California. \\ Berkeley, California
}

\begin{abstract}
Two beam choppers were constructed which produce an approximately square, $20 \mathrm{-ns}$ pulse of $3+-\mathrm{MeV}$ electrons out of the best portion of the $300-n s$ Astron beam or an 8- $\mu$ s microwave electron linac beam for injection into the electronring accelerator (ERA) compressor. The choppers are impedance-matched traveling-wave devices which deflect the beam with equal strength electric and magnetic forces, and are powered with either three-electrode spark gaps or thyratrons and a 20-ns pulse line. The electron beam is biased out of the beam-transport system with a dc magnetic field, and switched into it with the chopper.
\end{abstract}

\section{Introduction}

The ERA compressor required four turns of beam to be injected into it at the beginning of the compression cycle. The available electron accelerators - - $100-\mathrm{mA}$ microwave linac or the 400-A Astron accelerator--produced beam pulses of $8 \mu \mathrm{s}$ and $300 \mathrm{~ns}$ respectively, and in addition had relatively long rise times. The beam chopper was placed between the output of the accelerator and the input of the compressor to produce the desired beam pulse. The chopper worked in conjunction with a pulsed inflector system in the compressor.

Two complete chopper-inflector systems were built, one for use with each accelerator; each differed in the type of drive and the power required. Both systems produced beam pulses of less than 5-ns rise time and less than $2-n s$ total jitter between them. The first system was used with the microwave linac. The inflector spark gap was fired first, and a trigger signal was taken from it to fire a hydrogen thyratron which powered the chopper. The electron beam had a diameter of 1.25 in. at the chopper, enabling the required deflection to be achieved with $5 \mathrm{kV}$ and $0.5 \mathrm{MW}$ of power. In the second system, used with the Astron, the chopper was powered by a spark gap from which a pulse was taken to trigger the inflector. This chopper used 25 to $30 \mathrm{kV}$ and $6 \mathrm{MW}$ of power. In both systems the timing was adjusted by varying cable lengths. The chopper operation was similar in both systems, except for the power level, and subsequent discussion will be confined to the Astron system.

\section{Description}

Electrically, the chopper was similar to a length of 100- $\Omega$ transmission line operating in the TEM mode. The inner conductor of the line was a flat plate suspended above a flat, grounded pedestal and mounted within a 12-in. -diam stainless steel pipe. The dielectric throughout the chopper was vacuum. The plate separation varied from 3 in. at the input end to 3.5 in. at the output end. The pipe had end flanges for connecting it to the beam line, and coaxial ceramic feedthroughs for the high voltage at either end.

The deflecting pulse traveled in the direction opposite to the beam, and after passing through the chopper was terminated in a $100-\Omega$ resistive load. In the traveling-wave mode of operation the forces on the beam due to the electric and magnetic fields of the pulse are almost equal, differing only by a factor of $1 / \gamma^{2}$. The same deflection would result irrespective of the termination on the output of the chopper, but a termination on the line eliminates reflections and provides a convenient place for a voltage monitor. The 20-ns pulse length is too short for the magnetic-field distribution to change due to diffusion through conductors; therefore the field distribution across the beam aperture was the same as obtained electrostatically. The plates were 1.5 times as wide as the beam diameter. At the edges of the plates, copper rods were used to decrease the plate separation by $10 \%$ to slightly improve the field uniformity across the beam.

The rise time of the chopped beam was a function of the length of the deflecting section, the rise time of the pulse applied, and of the beam optics after the chopper. A step pulse would pass through the plates in $1.5 \mathrm{~ns}$, and would appear as a 3-ns-long, constant angular sweep on the beam due to the relative velocity of $2 \mathrm{c}$ between the beam and the pulse. The chopper was designed to give a deflection of slightly more than one beam diameter in a distance of 26 in. from the chopper, at which point a water-cooled beam stop was located. The 3-in.-diameter

\footnotetext{
This work was done under the auspices of the U. S. Atomic Energy Commission.
} 
beam size and 4-1/2-in. beam pipe after the beam stop combined to sharpen the rise time, because as the beam swept into the beam pipe it would strike the pipe for some distance past the "official" beam stop. The rise time of the $25-\mathrm{kV}$ pulse sent through the chopper was $2 \mathrm{~ns}$, and the fall time was almost as short, due to the overshoot caused by a shunt inductor at the input to the chopper. The main function of inductor was to flatten to $\pm 3 \%$ the top of the pulse which by itself had a slight rise due to the dispersion caused by the $50-\mathrm{ft}$ cable between the spark gap and the chopper. The beam rise time into the compressor was 2 to $5 \mathrm{~ns}$, depending on the tuning of the downstream transport systems and of the dc magnetic field which biased the beam out of the trans port channel. The pulse applied to the chopper was generated by a 7 -ft-long pulse line and a triggered spark gap. Two interchangeable pulsers were made to improve reliability. The spark gaps were pressurized with air to between 40 and 80 psi, and a slow leak was incorporated to continually purge the gap. The gaps were of a three-electrode design, with the middle electrode kept at half the charging voltage, and the spacings between the middle electrode and the high-voltage and ground electrodes were both approximately $1 / 16 \mathrm{in}$. In operation the middle electrode was pulsed to break down toward the ground side first, and after about $5 \mathrm{~ns}$ the second gap would break down under a considerable overvoltage. Only the second breakdown was apparent at the output, and the voltage rise time there was 2 ns.

A considerable degradation of rise time can be caused by the cable used between the chopper and the pulser. After passing through only $50 \mathrm{ft}$ of cable, the 20-ns pulse appears to have a $10 \%$, nearly linear rise on top of the pulse, and a. rounding off of the corners due to the skin impedance which decreases with time. An 0.8-in. -
OD solid-conductor cable was used to decrease the pulse distortion, and as already mentioned, a $10-\mu \mathrm{H}$ inductor was placed across the input to the chopper to compensate out the voltage rise. The overshoot at the end of the pulse caused by this inductor would only drive the beam further into the beam stop.

The large 400-A beam current passing through the chopper tended to affect the setting of the bias field required to deflect the beam into the beam stop. The beam upon entering the chopper would initially have electric and magnetic images, but the magnetic images due to the currents in the high-voltage plate would decay in a few nanoseconds, and the resulting image unbalance would bend the beam towards the high-voltage plate. The angular deflection caused by the pulse, however, would remain the same irrespective of beam current. The image effects can be eliminated by a completely symmetrical chopper with a pushpull drive, but space limitations prevented use of such a system.

The chopper was pulsed approximately $10^{6}$ times over a 5 -week period, during which a number of shakedown-type troubles appeared and were eliminated. The s park-gap electrodes showed less than $0.001-i n$. wear after the run, and generally required less maintenance than the hydrogen thy ratron pulsers used to trigger the spark gaps. The chopper provided an inexpensive way of obtaining precisely timed, short-rise-time beam pulses out of an accelerator not specifically designed for such service.

\section{Acknowledgment}

The authors wish to thank Messrs. David Vanecek and Gary Tidrick for the mechanical design of the chopper and the biasing coils. 
This report was prepared as an account of Government sponsored work. Neither the United States, nor the Commission, nor any person acting on behalf of the Commission:

A. Makes any warranty or representation, expressed or implied, with respect to the accuracy, completeness, or usefulness of the information contained in this report, or that the use of any information, apparatus, method, or process disclosed in this report may not infringe privately owned rights; or

B. Assumes any liabilities with respect to the use of, or for damages resulting from the use of any information, apparatus, method, or process disclosed in this report.

As used in the above, "person acting on behalf of the Commission" includes any employee or contractor of the Commission, or employee of such contractor, to the extent that such employee or contractor of the Commission, or employee of such contractor prepares, disseminates, or provides access to, any information pursuant to his employment or contract with the Commission, or his employment with such contractor. 
